\title{
Suitability of Citrus Species as Hosts of Sphaeropsis Tumefaciens Hedges ${ }^{1,2}$
}

\author{
S. D. Rodríguez, R. Rodríguez and P. L. Meléndez ${ }^{3}$
}

\begin{abstract}
The reaction of eight species of citrus and the chironja hybrid to inoculations with S. tumefaciens was evaluated in the greenhouse. All hosts developed disease symptoms, but their responses varied. Rough lemon was the host most severely affected by this pathogen, showing dieback symptoms 60 days after inoculation. The lowest disease index was observed in sour orange.
\end{abstract}

\section{INTRODUCTION}

In 1977 a disease attacking citron trees was detected in several commercial orchards located in the vicinity of Adjuntas, Puerto Rico. This malady, also known as citrus knot disease, is caused by the fungus Sphaeropsis tumefaciens Hedges. The pathogen has an ample geographical distribution and reports indicate that Jamaica is the most severly affected area. Because in Jamaica the disease citrus knot has curtailed the culture of West Indian lime and orange, we considered the citrus knot disease to represent a potential threat to our citrus production.

In 1982-83, the estimated farm value of citrus fruits in Puerto Rico, including limes, oranges, grapefruits and citrons, was around $\$ 4,592,000^{4}$. Because of the relative importance and economic potential of this commodity, it was thought advisable to evaluate the reaction of several citrus species commonly grown in Puerto Rico to inoculations with S. tumefaciens.

\section{MATERIALS AND METHODS}

The following species, Citrus aurantium L. (sour orange), C. sinensis (L.) Osbeck (orange) mative type, C. paradisi Macf. (grapefruit), C. grandis (L.) Osbeck (pummelo), C. jambhiri Lush.(rough lemon), C. limon (L.) Burm. f. (lemon 'Carlo'), C. reticulata Blanco var. Cleopatra (mandarine), chironja, and C. medica L. (citron), were chosen for this study. Selection was based on their qualities as fresh fruit and as rootstock. Approximately 50 seeds from each species were sown in 1:1

${ }^{1}$ Submitted to Editorial Board February 15, 1984.

${ }^{2}$ Part of a thesis submitted to the Graduate School in partial fulfillment of the requirements for the Master of Science degree in Crop Protection. This research was sponsored by Agricultural Experiment Station Project C-486.

${ }^{3}$ Graduate Student, Assistant Phytopathologist, and Phytopathologist, College of Agricultural Sciences, Crop Protection Department, University of Puerto Rico, Mayagüez, P. R.

${ }^{4}$ Personal communication from Agricultural Statistics, Puerto Rico Department of Agriculture. 
mixture of peat moss and perlite. After 1 month they were transplanted to pots with equal parts of organic matter, sand and alluvial soil. Fertilizer 12-6-16 at the rate of $1.5 \mathrm{~g} /$ pot was applied at transplanting. Whenever necessary plants were sprinkle irrigated. At the end of 3 months, five plants from each species were randomly selected and inoculated in the greenhouse with the citron isolate of $S$. tumefaciens. For inoculation, cups of paraffin paper were placed at the fourth stem node, counting downwards from the apical meristem (fig. 1-A). Two $\mathrm{cm}^{3}$ of a spore suspension of $152 \times 10^{4}$ spores $/ \mathrm{cm}^{3}$ was added to each cup. Inoculum was prepared by scraping the surface of 8-day-old cultures and drenching the plate with distilled water. The cultures were grown in Czapek sol agar and sporulated actively. The spores thus suspended were collected in flasks after being filtered through cheesecloth. During the first $72 \mathrm{hr}$, plants were kept covered with clear plastic bags. The cups were kept on the inoculation site until appearance of the first disease symptoms. A disease index, based in the following formula, was employed.

$$
\mathrm{DI}=\frac{\text { Sum of }(\text { disease class } \times \text { number of plants in that class })}{\text { Total number of plants } \times \text { highest disease class }} \times 100
$$

Ratings were determined by using as criteria knot formation at inoculation site and evidence of secondary growths in which $0=$ no disease symptoms, $1=1-20 \%, 2=21-40 \% ; 3=41-60 \% ; 4=61-80 \%$ and $5=$ $81-100 \%$ of stem area infected.

\section{RESULTS AND DISCUSSION}

All species were attacked by the fungus although differences in their reactions were observed. Twelve days after inoculation most of the species, except $C$. grandis and C. reticulata, had developed slight swellings in the inoculated area. The following tabulation shows the disease index of the species inoculated.
Host
C. jambhiri Lush.
C. medica L.
C. limon (L.) Burm. f.
C. sinensis $\times C$. paradis $^{6}$
C. reticulata Blanco
C. sinensis (L.) Osbeck.
C. paradisi Macf.
C. grandis (L.) Osbeck
C. aurantium $\mathrm{L}$.

Disease Index
$72 \mathrm{a}^{5}$
$62 \mathrm{a} \mathrm{b}$
$62 \mathrm{a} \mathrm{b}$
$56 \mathrm{a} \mathrm{b} \mathrm{c}$
$44 \mathrm{a} \mathrm{b} \mathrm{c} \mathrm{d}$
$30 \mathrm{~b} \mathrm{c} \mathrm{d}$
$28 \mathrm{~cd}$
$26 \mathrm{~cd}$
$18 \mathrm{~d}$

\footnotetext{
${ }^{5}$ Means in the same column followed by one or more letters in common do not differ significantly at the .05 level.

${ }^{6}$ Chironja, a possible natural cross.
} 

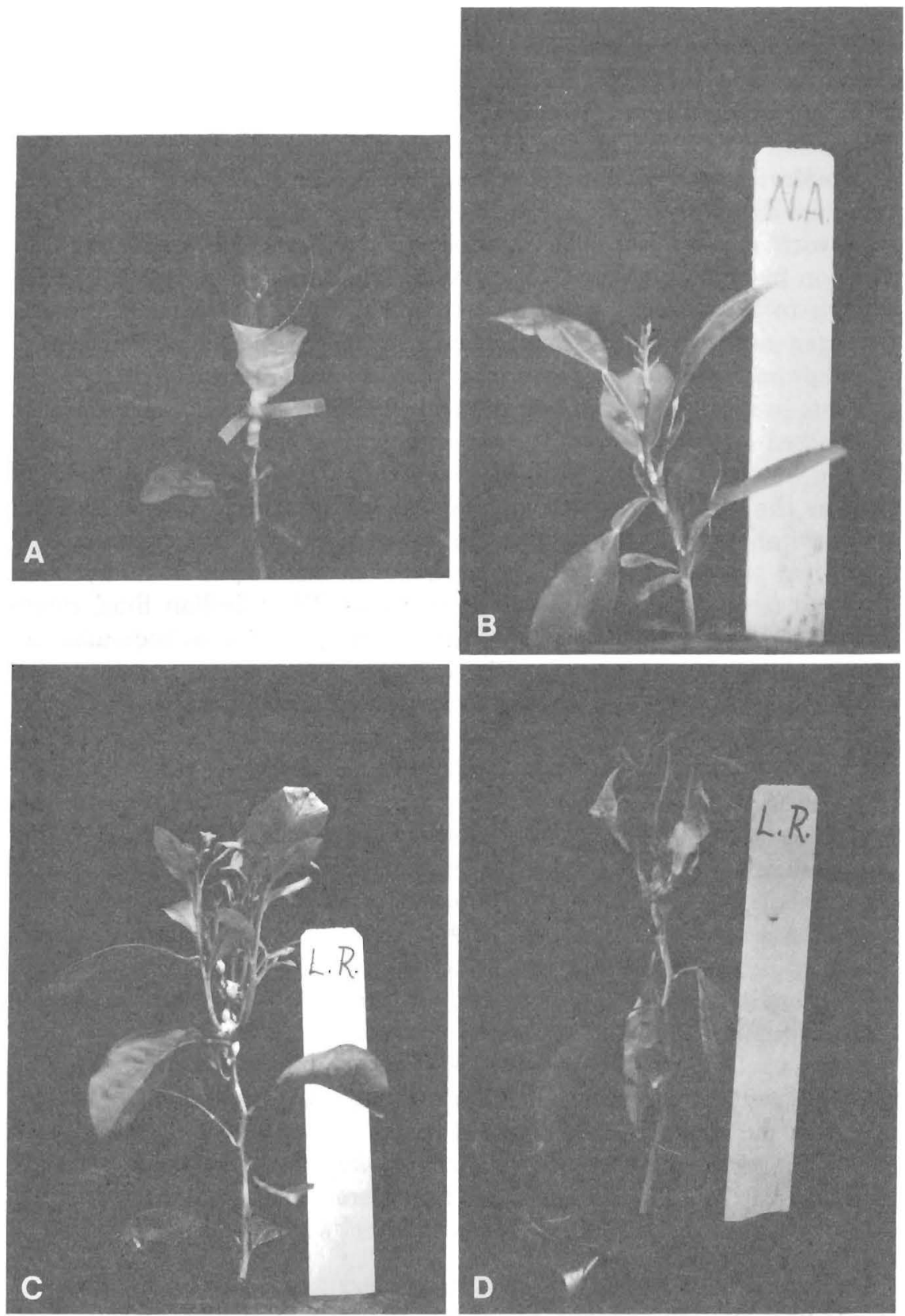

FIG. 1.-A. Cups of paraffin paper used in the inoculations. Base of the cup is sealed with rubber band. B. Resistant reaction of $C$. aurantium to invasion by the pathogen. $C$. Reaction of susceptible host $C$. jambhiri. showing profuse knot formation at and above inoculation site, D. showing branch decline symptom 60 days after inoculation. 
C. jambhiri, was the most susceptible host with disease index of 72 , and C. aurantium had the lowest disease index, 18 (fig. 1-B). No significant differences among C. jambhiri, C. medica, C. limon, chironja and C. reticulata were detected. However, the disease index in C. reticulata was almost half of that recorded in C. jambhiri. Two months after inoculation, C. jambhiri (fig. 1-C and D), C. medica, C. limon, and C. reticulata, exhibited dieback of limbs. The response of $C$. reticulata indicates that even with a relative low knot incidence, diseased hosts succumb to invasion by the pathogen. Consequently, knot incidence by itself is not enough to determine disease severity. All symptoms induced by the pathogen must be taken in consideration when evaluations are conducted.

Symptoms of disease caused by $S$, tumefaciens are usually expressed as knots in stem and branches of infected trees with subsequent dieback of affected organs. However, new evidence on the importance of this disease was revealed by Blázquez and Hunt. ${ }^{7}$ They reported S. tumefaciens as the causal organism of rough lemon rootstock disease, causing $40 \%$ mortality on grafted 4-year-old Valencia trees. Also, these workers conducted successful cross inoculations with isolates of $S$. tumefaciens obtained from diseased limbs of Orthanique, West Indian lime, rough lemon, and with a monosporic culture from rough lemon rootstock. As in our trials, rough lemon was the most susceptible host reacting with equal susceptibility to all isolates tested. Since most of the species in our trials are commonly used as rootstocks, their reaction to the attack by this pathogen should be taken into consideration when selecting rootstock material.

Studies on the host-range of this fungus with isolates from West Indian lime and orange were conducted by Hedge and Tenny. ${ }^{8}$ Inoculations with the lime isolate in pummelo, Poncirus trifoliata $(=C$. trifoliata) and tangerine were successful, although the tumors induced were small. However, when this isolate was tested on lemon cv. American Wonder, $100 \%$ knot formation was obtained. In trials with the orange isolate, typical tumors were induced in lime and pummelo.

Sphaeropsis knot disease has been reported in Puerto Rico as very seriously only in commercial citron orchards in Adjuntas. ${ }^{9}$ However, a new host has already been detected in the same locality. Knots caused by this fungus were observed in C. aurantifolia Swing growing in a private backyard garden. This finding and those herein reported clearly demonstrate the capacity of $S$. tumefaciens to infect several citrus species. The

${ }^{7}$ Bláquez, C. H. and P. Hunt, 1967. Sphaeropsis knot, a disease of rough lemon rootstock, Proc. Fl. State Hort. Soc. 79 (344-350).

${ }^{8}$ Hedges, F. and L. S. Tenny, 1912. A knot of citrus trees caused by Sphaeropsis tumefaciens Hedges, USDA Bureau Plant Industry Bull. 247:1-69.

${ }^{9}$ Rodriguez, R. and P. L. Meléndez, 1979. Knot disease of citron (Citrus medica L.) in Puerto Rico caused by Sphaeropsis tumefaciens Hedges, (Abstr.) Memorias SOPCA. 
capability of this fungus to infect does not vary among the hosts studied but its virulence does.

\section{RESUMEN}

Se evaluó la reacción de ocho especies y un híbrido de cítricas a inoculaciones con S. tumefaciens. Todos mostraron ser huéspedes del patógeno, aunque se detectaron variaciones en sus respuestas a la invasión por este hongo. El limón rugoso, fue el huésped más severamente atacado manifestando síntomas de muerte regresiva a los 60 dias después de la inoculación. En la naranja agria se obtuvo el indice de enfermedad más bajo. 